\title{
Study of hematological parameters among newborns with perinatal asphyxia
}

\author{
Koreti S. ${ }^{1}$, Eske G.S. ${ }^{2}$, Gaur A. ${ }^{3}$, Gupta A. ${ }^{4}$ \\ ${ }^{1}$ Dr. Sunita Koreti, Professor, ${ }^{2}$ Dr. Gunvant Singh Eske, Assistant Professor, ${ }^{3}$ Dr. Ajay Gaur, Professor and Head, \\ ${ }^{4}$ Dr. Akriti Gupta, Post graduate student, all authors are affiliated with Department of Pediatrics, G.R. Medical College, \\ Gwalior (MP), India.
}

Corresponding Author: Dr. Gunvant Singh Eske, Assistant Professor, Department of Pediatrics, G.R. Medical College, Gwalior. Email-gunvant987@gmail.com

\begin{abstract}
The aim of this original research article was to identify the blood parameters as predictors of perinatal asphyxia and its correlation with severity of asphyxia. Setting: Postnatal Wards and Sick newborn unit of Pediatric Department, KamlaRaja, Gwalior. Design: A prospective case control study. Participants: 100 cases and 100 controls enrolled based on the selection criteria, on day 1 of life. Methods: On day 1of delivery newborns were enrolled, who fulfilled the inclusion criteria. Complete history, physical examination and neurological signs were recorded on a predesigned proforma. Hypoxic ischemic encephalopathy (HIE) Staging done. Cord blood samples were collected on day 1 and results analyzed. Results: The present study included 100 cases and 100 controls. Out of the total 100 cases, 23\% (23) were HIE stage-I, 46\% (46) were stage-II and 31\% (31) were of stage -III Significant difference is seen in mean values of nucleated RBCs among the cases and controls ( $p$ value $<0.001$ ). It was $10.85 \pm 6.39$ and $5.91 \pm 3.60$ among cases and controls respectively. Leucocyte count was found $17.06 \pm 7$ among cases while among controls mean was $14.14 \pm 4.15$, which was significant. Similarly, significant difference was found in mean $\mathrm{Hb}$ among cases and control group. Polychromatophilia was found significant ( $p$ value $<0.001$ ) when compared between cases and controls and among cases themselves. The value of Positive predictive Value and Negative Predictive Value are maximum for n-RBCs. Accuracy for determining the mortality is also maximum. It is seen that area AUC for n-RBCs is maximum i.e. 0.795 which makes it the best blood parameter which correlates with mortality. Conclusions: Blood parameters are altered in perinatal asphyxia and can be used to predict the severity and outcome.
\end{abstract}

Keywords: Perinatalasphyxia, Hypoxicischaemic encephalopathy, Nucleated RBCs, Polychromatia, mortality predictors

\section{Introduction}

Birth asphyxia, although the correct definition is imprecise, is an insult to the fetus or newborn due to failure to breath or breathing poorly leading to decrease oxygen perfusion to various organs [1]. WHO has defined perinatal asphyxia as a "failure to initiate and sustain breathing at birth". Birth asphyxia refers to a condition of hypoximea, hypercapnia and insufficient blood perfusion of new born during labour and birth. Perinatal asphyxia is one of the significant causes of morbidity and mortality. According to WHO estimates, around 3\% of approximately 120 million infants born every year in developing countries, develop birth asphyxia. It is estimated that some $9,00,000$ of these newborns die each year[2].

Manuscript received: $7^{\text {th }}$ March 2018

Reviewed: $14^{\text {th }}$ March 2018

Author Corrected: $22^{\text {nd }}$ March 2018

Accepted for Publication: $27^{\text {th }}$ March 2018
Globally, hypoxia of the new born (birth asphyxia) or the fetus (fresh stillbirth) is estimated to account for $23 \%$ of the 4 million neonatal deaths and $26 \%$ of the 3.2 million stillbirths each year [2]. An estimated 1 million children who survive birth asphyxia live with chronic neuro development morbidities, including cerebral palsy, mental retardation, and learning disabilities. According to these previous statics, we found that Birth asphyxia is a major cause of neonatal deaths. Perinatal asphyxia has an incidence of 1 to 6 per 1,000 live fullterm births and represents the third most common cause of neonatal death $(23 \%)$ after preterm birth $(28 \%)$ and severe infections $(26 \%)$.

Many preconceptional, antepartum and intrapartum risk factors have been shown to be associated with perinatal asphyxia [3]. 
Birth asphyxia has varying effects on the neonatal brain depending upon the gestational age of the baby and the severity and time of onset of the asphyxiating event (s) which can occur at any point in the infant's antepartum, intrapartum, and postpartum life. Although, hypoxicischemic encephalopathy (HIE) is the hallmark of severe asphyxia, such cases can often exhibit multisystem failure involving the heart, kidneys and gastrointestinal systems.

This in itself may pose difficult problems whereby optimal treatment of one system, e.g., volume expansion, may adversely affect another, e.g., acute renal failure. Hence care must be taken to provide general supportive measures while avoiding further insult to an already compromised system. For this, close monitoring is imperative.

Guidelines for neonatal resuscitation, such as those endorsed by WHO and the American Academy of Pediatrics, represent a standard practice set that improves outcomes in asphyxiated new borns. These algorithms stress the importance of drying, stimulating and warming babies in distress, as well as clearing their airways. In the face of persistent apnea or bradycardia, ventilation with the use of bag-and-mask or equivalent device is indicated and is felt by many to constitute the critical step in managing asphyxiated infants [4]. Newborns have a remarkable ability to withstand hypoxia and many improve rapidly with timely implementation of these techniques. Few infants go on to require chest compressions or pharmaceutical administration.

Hematopoietic system changes are observed as a complication of asphyxia. Altered biophysical characteristics of blood e.g. changes in the structure and function of erythrocytes, leucocytes and thrombocytes can be caused by asphyxia [5]. Hematologic adaptations in the fetus include short term and long-term responses [6]. Acute hypoxia either in utero or during perinatal period causes short term responses like reduction of body temperature, reduction in heart rate, and redistribution of circulation. Chronic hypoxemia involves bone marrow resulting in polycythemia, thrombocytosis and thrombocytopenia.

Polychromatophilia is defined as a condition where there is an abnormally high number of red blood cells found in the blood stream as a result of being prematurely released from the bone marrow during blood formation. It is usually a sign of bone marrow stress as well as immature red blood cells.
Thisstudy was conducted to evaluate the various hematological changes following asphyxia and also to compare these variables among themselves in their role in assessing the severity of asphyxia. The hematological parameters chosen for the study are; 1 . Nucleated RBCs (n-RBCs), 2. Platelet count, 3. Total leucocyte count, 4. Hemoglobin and 5. Hematocrit.

\section{Methods}

The objective of the study was to hematological parameters as predictors of perinatal asphyxia and to assess their correlation with severity. Setting of the study was SNCU, Department of Paediatrics, Post-natal wards, Kamla Raja Hospital, Gajra Raja Medical College, Gwalior. Study design: Prospective Crosssectional study. Sample size: 100 cases 100 control. Duration: One year (July 2015-July 2016). Participants: 100 newborns admitted in sick newborn unit on day 1 who fulfill the selection criteria are taken as cases. Similarly, 100 newborns (first Post-natal day) of postnatal wards fulfilling the selection criteria, as controls. consent: Informed and written consent is taken from the attender. Material: Thermometer, EDTA vials, heparinised syringes, glass slides, surgical blades and cord clamps.

Inclusion criteria- All full-term newborn

- Who need resuscitation on admission

- With distress

- With Meconium Aspiration (non-vigorous)

- With history of Delayed cry

\section{Exclusion criteria}

- Preterm neonates

- VLBW

- Blood culture proven sepsis

- Neonates with congenital malformations

A newborn, based on the inclusion and exclusion criteria, was chosen as a case or a control. For enrolment of a case or a control, informed and written consent was taken and details of mother and father's name, address; name and signature of attender bringing the baby; also, the details of the birth, details of any maternal complications like bad obstetric history etc. and examination of the newborn, as mentioned in a preformed proforma were recorded.

Clinical staging done based on Levene staging for HIE and newborns were classified as stage I, II or III. Two blood samples were taken from the umbilical cord of 
the newborn- for arterial blood gas analysis and for blood parameters used in the study (i.e. n-RBCs, platelet count, total leucocyte count, haemoglobin and hematocrit); both taken in EDTA vials.

Sample for ABGA and blood parameters were sent within the hospital. ABGA was done using blood gas analyser. Blood counts were determined by an automatic analyzer using an optical system. Hemoglobin was measured calorimetrically. Peripheral smear was done for nucleated RBCs (n-RBCs) and for manual platelet count. Values obtained were compared with the normal values.
Clinical examination and HIE Staging was done on day 1 and day 3. Correlation was done with all haematological parameters and $\mathrm{pH}$ and HIE staging to assess the severity and compared the outcome among case.

Statistical analysis- Normally distributed variables were compared using the unpaired $t$ test where as Mann-Whitney $U$ test was used for variables not distributed normally. Variables wereanalyzed using either the chi square test or Fisher's exact test ANOVA was used to evaluate the significance of the differences in severity of HIE among cases.

\section{Result}

This study was a Prospective case control study, conducted on 100 cases and 100 controls, admitted in sick new born unitand postnatal wards of hospital, over a period of one year from July 2015 to July 2016. Performa was filled and birth data was recorded both for cases and controls. Out of the total 100 cases, 23\% (23) were HIE stage- I,46\% (46) were stage-II and 31\% (31) were of stage- III. Among all asphyxia new borns 76\% were delivered by normal vaginal delivery and $22 \%$ by LSCS delivery. On comparing weight we found that $91 \%$ were 2500 gm- 3000 gm and $9 \%$ were 3000 gm$3500 \mathrm{gm}$. (Table 1) significant difference is seen in mean values of nucleated RBCs among the cases and controls (p value $<0.001$ ). Among cases mean value was $10.85 \pm 6.39$, while among control group mean was $5.91 \pm 3.60$.

Mean Total Leucocyte count was found $17.06 \pm 7$. Among cases while among control mean was $14.14 \pm 4.15$, which was significant. Similarly, significant difference was found in mean $\mathrm{Hb}$ among cases and control group. On comparing hematocrit and platelet count results were insignificant (Table2). An association of polychromatia and perinatal asphaxia was found in our study. Among both group $24 \%$ cases of birth asphaxia had polychromatia while only $2 \%$ had polychromatia among control group which was found significant(Graph1)

Table-1-Birth data among cases and controls.

\begin{tabular}{|c|c|c|c|c|c|}
\hline \multirow[t]{2}{*}{ S.No. } & \multirow[t]{2}{*}{ Characteristic } & \multicolumn{3}{|c|}{ Cases(100) } & \multirow{2}{*}{$\begin{array}{c}\text { Control } \\
\text { (100) }\end{array}$} \\
\hline & & $\begin{array}{c}\text { HIE-I } \\
(23) \\
\text { N(\%) }\end{array}$ & $\begin{array}{c}\text { HIE-II } \\
(46) \\
\text { N(\%) }\end{array}$ & $\begin{array}{c}\text { HIE-III } \\
\text { (31) } \\
\text { N(\%) }\end{array}$ & \\
\hline \multirow[t]{3}{*}{1.} & \multicolumn{5}{|c|}{ Place of delivery } \\
\hline & - Inborn & 15 & 34 & 19 & 68 \\
\hline & - Outborn & 08 & 12 & 12 & 32 \\
\hline \multirow[t]{4}{*}{2.} & \multicolumn{5}{|c|}{ Mode of delivery } \\
\hline & - Normal vaginal & 15 & 30 & 15 & 76 \\
\hline & - Assisted & 02 & 07 & 10 & 02 \\
\hline & - Caesarean section & 06 & 09 & 06 & 22 \\
\hline \multirow[t]{4}{*}{3.} & \multicolumn{5}{|c|}{ Gestational age(weeks) } \\
\hline & - $37-40$ & 21 & 44 & - & 94 \\
\hline & - $40-42$ & 02 & 02 & 31 & 05 \\
\hline & - $>42$ & - & - & - & 01 \\
\hline \multirow[t]{3}{*}{4.} & \multicolumn{5}{|c|}{ Birth weight(g) } \\
\hline & - $2500-3000$ & 22 & 43 & 29 & 91 \\
\hline & - $3000-3500$ & 01 & 03 & 02 & 9 \\
\hline
\end{tabular}


Table-2: Correlation between blood parameters and case and control

\begin{tabular}{|c|c|c|c|}
\hline \multirow{2}{*}{ Parameter } & Controls & Cases & \multirow{2}{*}{ p-value } \\
\cline { 2 - 4 } & Mean \pm SD & $10.85 \pm 6.39$ & $<0.001$ \\
\hline $\begin{array}{c}\text { Nucleated RBCs/ } \\
\text { 100 WBCs }\end{array}$ & $5.91 \pm 3.60$ & $16.86 \pm 2.48$ & 0.015 \\
\hline Hemoglobin & $16.00 \pm 2.52$ & $51.01 \pm 6.22$ & 0.081 \\
\hline Hematocrit & $49.24 \pm 7.98$ & $2.17 \pm 0.72$ & 0.776 \\
\hline $\begin{array}{c}\text { Platelet count } \\
(\text { lacs/mm3) }\end{array}$ & $2.20 \pm 0.71$ & $17.06 \pm 7.18$ & 0.001 \\
\hline $\begin{array}{c}\text { TLC } \\
\left(\mathrm{X} 10^{9} / \mathrm{L}\right)\end{array}$ & $14.14 \pm 4.15$ & Mean & \\
\hline
\end{tabular}

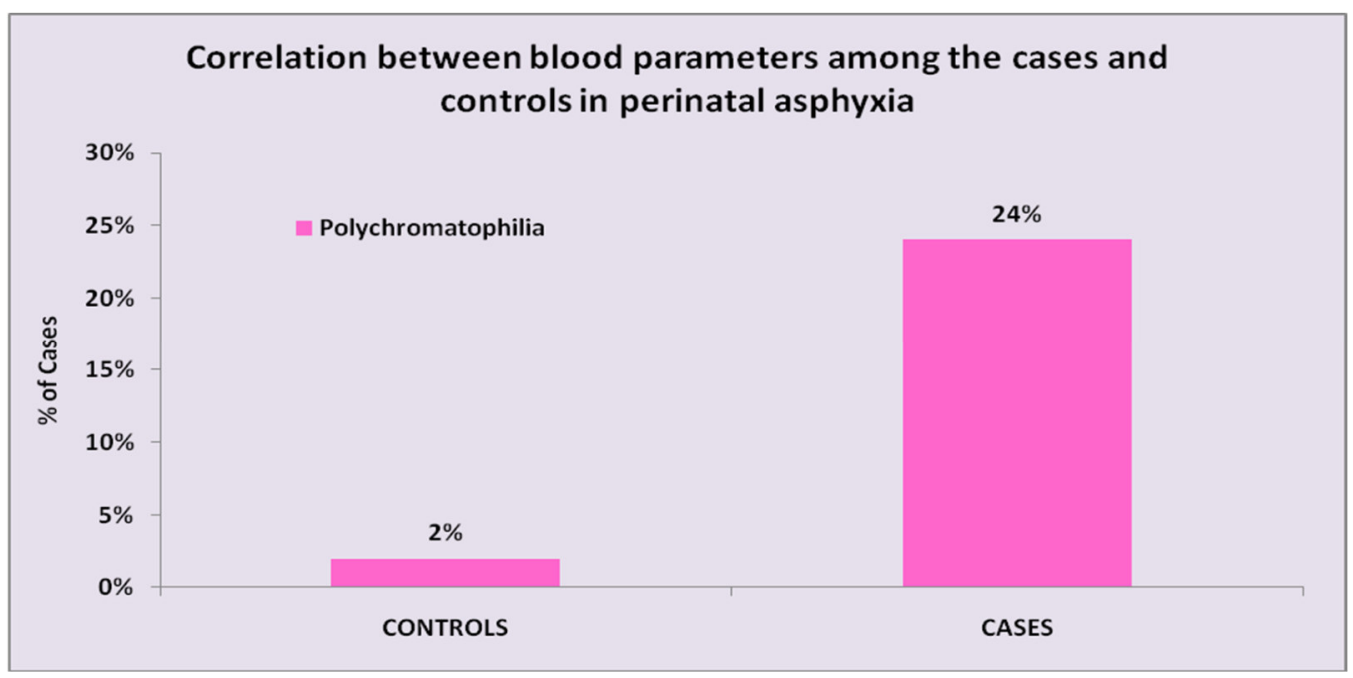

Graph-1: Correlation of polychromatophilia with cases and controls

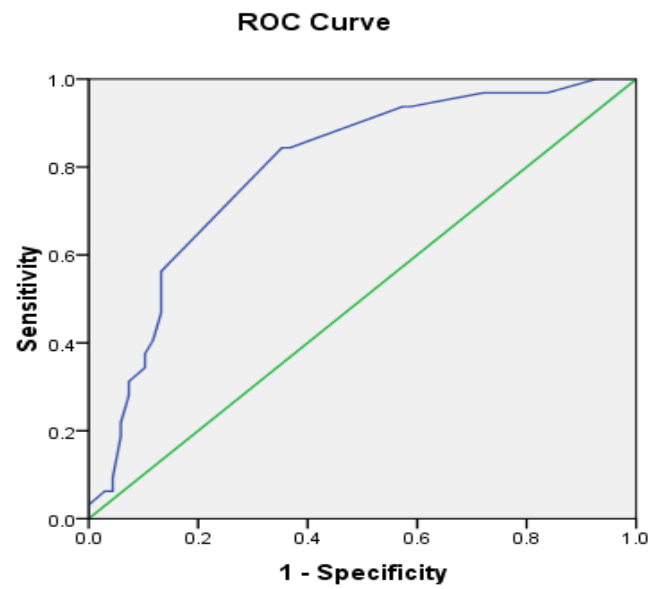

Diagonal segments are produced by ties.

Graph-2: Receiver operating characteristic (ROC) curves of blood parameters for predicting the mortality-

(a) ROC curve for $n-\mathrm{RBCs} / 100 \mathrm{WBCs}$
ROC Curve

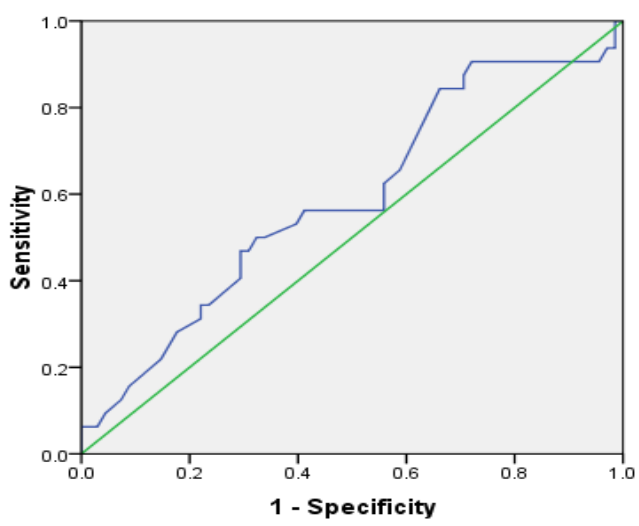

Diagonal segments are produced by ties.

(b) ROC curvefor hemoglobin 


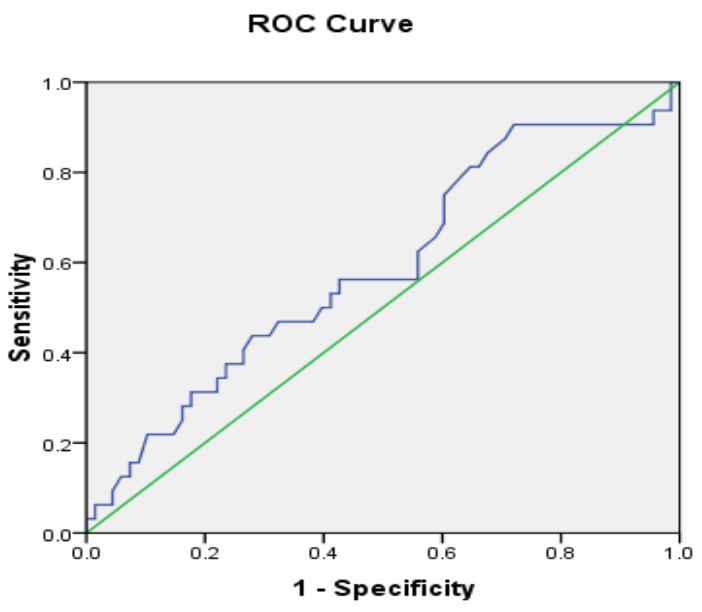

Diagonal segments are produced by ties.

(c) ROC curve for hematocrit

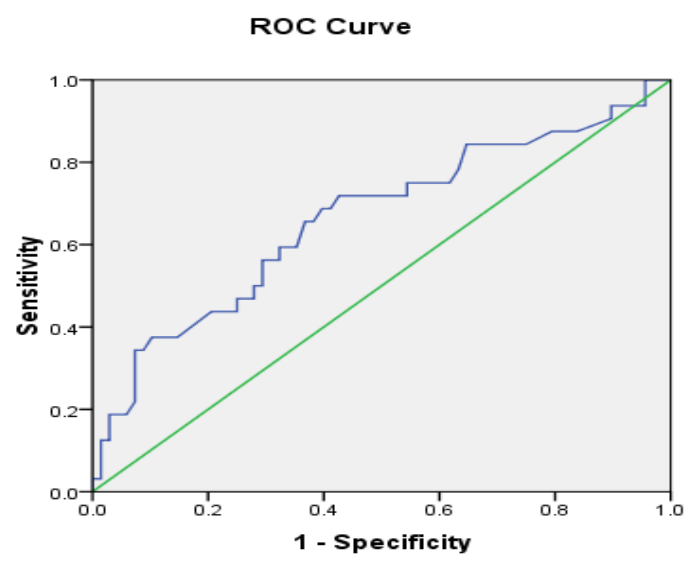

Diagonal segments are produced by ties.

(e) ROC curve for total leucocyte count
ROC Curve

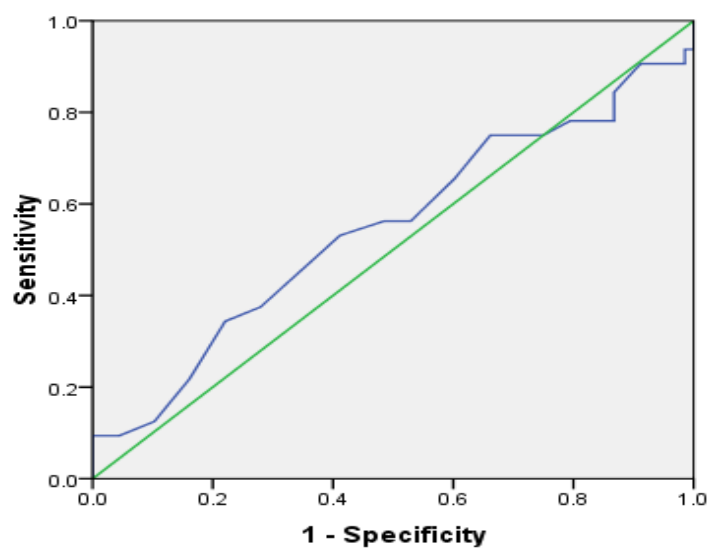

Diagonal segments are produced by ties.

(d) ROC curve for platelet count

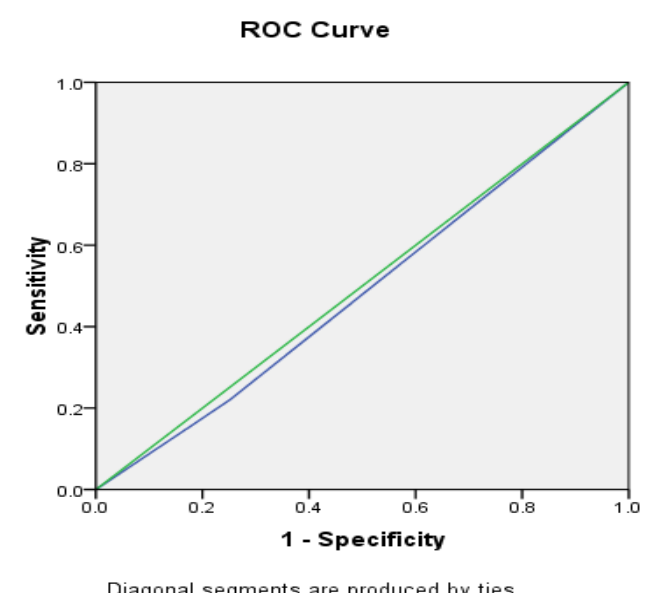

(f) ROC curve for polychromatophilia

We also compare the sensitivity and specificity of all Haematological parameters to predict severity. Ratio-RBC /100 WBCs more than or equal to 9.5 , has sensitivity and specificity of $84.4 \%$ and $64.7 \%$ respectively. This is followed by TLC $\left(\mathrm{x} 10^{9}\right)$ which has sensitivity and specificity of $71.9 \%$ and $55.9 \%$ respectively for value more than equal to $15.75 . \mathrm{p}$ value is also significant. The value of Positive predictive Value and Negative Predictive Value are maximum for n-RBCs. Accuracy for determining the mortality is also maximum. It is seen that area AUC for n-RBCs is maximum i.e. 0.795 which makes it the best blood parameter which correlates with mortality (table3, curve 2a,b,c, d,e,f)

\section{Discussion}

According to WHO, 4-9 million newborns develop birth asphyxia each year and at least the same number develop severe consequences such as epilepsy, cerebral palsy and developmental delay [7]. Major manifesttations of asphyxia are produced as a result from a combination of hypoxia and ischemia of the brain and other vital organs. It occurs due to combination of vasodilatation and vasoparalysis [7]. The study was done with the aims and objective to identify the various hematological parameters which are affected in perinatal asphyxia and to compare these parameters, for their role in assessment of severity of asphyxia and outcome. In our study significant difference was seen in mean values of nucleated RBCs among the cases and controls ( $p$ value $<0.001$ ). The ratio of $n-R B C s / W B C$ was significantly correlated with severity of asphyxia. These results are found similar to with results of study done by Ruchi Rai et al where the immediate and short- 
term outcomes of newborns with perinatal asphyxia were studied in relation to the nucleated red blood cell count (n-RBCs) at admission. The mean (SD) ratio of $\mathrm{nRBC} / 100 \mathrm{WBC}$ (white blood cells) was significantly higher in sequelae group than normal, it was 9.8 (98.9) and $2.9(43)$ respectively $(\mathrm{P}=0.001)[8]$.

Chronic or acute hypoxia is one of the most important causes of increased nucleated RBC count (NRBC count) in a neonate [9]. In the present study also statistically, significant difference was found in number of n- RBCs among the three stages of HIE with highest number seen in stage III. Also, significant difference was found between cases and controls. Similar observations were made by Phelan et al and Korst et al $[10,11]$.

Similar observation by Geetika et al [12] that the mean $\mathrm{nRBC} / 100$ WBC count for case group was $10.3400 \pm 3.87883$ and for the control group was $5.7000 \pm 2.33212$. This difference was highly significant ( $\mathrm{p}$ value) concluded that intra uterine hypoxia causes release of erythropoietin leading to increased mitosis of erythroid precursors and their release in the fetal circulation. This holds true for both acute as well as chronic hypoxia though the exact mechanism of increased peripheral $\mathrm{nRBC}$ still remains elusive [12].

Fanaroff [13] concluded that normoblasts could enter the blood stream within 30 minutes of a severe hypoxic injury. Korst et al [14] and Phelan et al [15] found increased RBCs after acute catastrophic intrapartum events. The duration of these catastrophic events was undoubtedly less than one hour in most cases

Phelan et el found the mean nRBC/100 WBC count of $3.4 \pm 3.0$ in non asphyxiated neonates and the count was $34.5 \pm 6.83$ in asphyxiated neonates [4]. Bunocore et al [16], Ghosh et al [17] and Ferns et al [18] concluded that nRBC count at birth not only reflects a haematological response of infant to perinatalasphyxia but is also a reliable marker of perinatal brain damage.

The rate of hemoglobin synthesis and of $\mathrm{RBC}$ production fall dramatically after birth and remain low for the first two weeks of life, probably in response to thesudden increase in tissue oxygenation at birth. The physiological rise in red cell production begins several weeks later [19].

In the present studyno significant difference was seen in hematocritwhen comparison was done between cases and controls. Value of hemoglobin was $17.43 \pm 2.18$,
$17.45 \pm 1.81,15.55 \pm 3.07 \mathrm{~g} / \mathrm{dl}$ among stage I, II and III of HIE. While it was $52.50 \pm 6.57,52.56 \pm 5.46$ and $47.62 \pm 5.85 \%$ respectively for stage I, II and III for hematocrit. Comparison was significant $(\mathrm{p}$ value $=$ 0.001 ) with values of hemoglobin and hematocrit decreasing in perinatal asphyxia. This may be caused by intensification of oxidative stress during prenatal and direct postnatal period as well as by blood redistribution orbyhemorrhage. Similar to the study done by Ramesh $\mathrm{R}$ Pol et al, there is significant difference found in the values of hemoglobin between cases and controls [20]

In a study done by I. Brucknerova et al [21], after evaluation of red blood components in peripheral blood on the first day of life, they found statistically significant decrease of erythrocytes and hemoglobin in asphyxiated term newborns when compared with the controls. Similar finding was seen in study done by Ramesh R Pol et al [22].

In this study, no significant difference was found in the platelet count between cases and controls and also when cases were compared among themselves. This is similar to the study done by I. Brucknerova et al and Phelan et al $[10,23]$

In our study, polychromatophilia was a significant finding present in $32 \%$ of HIE cases as compared to only $2 \%$ in controls. This was found to be statistically significant and thus can be used to assess the severity of asphyxia. No such study is done in the past studying the role of polychromatophilia in perinatal asphyxia.

\section{Conclusion and recommendation}

Haematological parameters TLC, Haemoglobin, nucleated RBCs are good markers for asphyxia. Polychromatia is also early predictor of asphaxia. Among all $n$ RBCs and Ratio of $n$ RBC/100 WBC hasgood prognostic value.So with these conclusions this study recommends that-

1. Along with the basic blood investigations, n-RBCs and Polychromatophilia should also be done in each case of perinatal asphyxia

2. These parameters should be correlate well with the clinical findings.

3. n-RBCs and n-RBC / WBC ratio should be used as prognostic indicator for HIE.So these parameters should be done immediately after delivery with cord blood.

4. Both prognostic parameters $n-R B C$ and n-RBC / WBC ratio should be repeated after 48-72 hours. 


\section{What was already known?}

- Total leucocytecount, haemoglobin and hematocrit are also good markers for prediction and correlation of severity.

- Among the parameters chosen, nucleated RBCs are the best predictors of perinatalasphyxia. Also, these correlate best with the outcome.

- These prove to be good, early and feasible markers for the prediction of hypoxia-ischaemia event.

\section{What study adds?}

- Polychromatophilia can be used as predictor of perinatalasphyxia.It does not correlate with outcome of asphyxia.

- Clinical parameters chosen correlate with stage of encephalopathy and along with laboratory parameters help in estimating an ischaemia event and predicting the outcome.

\section{Declaration}

Funding: Nil, Conflict of interest: None initiated, Perission from IRB: Yes

Contribution details- All authors were involved in concept, design of study, data collection and critical review

\section{References}

1. H. Muhammad Aslam, Shafaq Saleem, Rafia Afzal,et al. Risk factors of birth Asphyxia. Italian Journal of Pediatrics 2014;140:94. https://doi.org/10.1186/s13052014-0094-2

2. State of World's children, UNICEFF Report: Maternal and Newborn health; 2009.

3. de Haan M, Wyatt JS, Roth S, Vargha-Khadem F, Gadian D, Mishkin M. Brain and cognitive-behavioural development after asphyxia at term birth. Dev Sci. 2006 Jul; 9 (4):350-8.

4. Jonathan M Spector \& Subhash Daga. Preventing those so-called stillbirths. Bulletin of the World Health Organization 2008 April, 86 (4).

5. Curtin WM, Shehata BM, Khuder SA, et al. The feasibility of using histologic placental sections to predict new born nucleated red blood cell counts. Obstretic Gyaenecoly, 2002 Aug; 100(2):305-10.
6. Rolfo A, Maconi M, Cardaropoli S, Biolcati M, Danise P, Todros T. Nucleated red blood cells in termfetuses: reference values using an automated analyzer.Neonatology.2007;92(3):205-8.Epub2007Apr 30

7. Azra Haider B, Bhutta ZA. Birth asphyxia in developing countries: currentstatus and public health implications. Curr Probl Pediatr Adolesc Health Care. 2006 May-Jun; 36(5):178-88.

8. Ruchi Rai, Gaurav Tripathi And Dk Singh. Nucleated RBC Count as Predictor of Neurological Outcome in Perinatal Asphyxia' Indian journal of pediatrics, 2014 March, vol 51,231.

9. Hermansen MC. Nucleated red blood cells in the fetus and newborn. Arch Dis Child Fetal Neonatal Ed. 2001 May; 84 (3):F211-5.

10. Phelan JP, Kirkendall C, Korst LM, Martin GI. Nucleated red blood cell and platelet counts in asphyxiated neonates sufficient to result in permanentne urologic impairment. J Matern Fetal Neonatal Med. 2007 May; 20(5):377-80.

11. Korst LM, Phelan JP, Ahn MO, Martin GI. Nucleated red blood cells: an update on the marker for fetal asphyxia. Am J Obstet Gynecol. 1996 Oct;175 (4 Pt 1): 843-6.

12. GTomar, Sikarwar S, Gupta S. The Correlation Of Clinical Perinatal Asphyxia With Counts Of Nrbc /100 Wbc In Cord Blood. Webmed Central Obstetrics And Gynaecology, 2011Jan;2(1):WMC001511.

13. Jones G, Steketee RW, Black RE, Bhutta ZA, Morris SS; Bellagio Child Survival Study Group. How manychilddeaths can we prevent this year? Lancet. 2003 Jul 5; 362(9377):65-71.

14. Korst LM, Phelan JP, Ahn MO, Martin GI. Nucleated red blood cells: an update on the marker for fetal asphyxia. Am J Obstet Gynecol. 1996 Oct;175 (4 Pt 1):843-6.

15. Phelan JP, Korst LM, Ahn MO, Martin GI. Neonatal nucleated red blood cell and lymphocyte counts in fetal brain injury. Obstet Gynecol. 1998 Apr; 91(4):485-9.

16. Buonocore G, Perrone S, Gioia D, Gatti MG, Massafra C, Agosta R, Bracci R. Nucleated red blood 
cell count at birth as an index of perinatal brain damage. Am J Obstet Gynecol. 1999 Dec;181(6):1500-5.

17. Ghosh B, Mittal S, Kumar S, Dadhwal V.Prediction of perinatalasphyxia with nucleated red blood cells in cord blood of newborns. Int J Gynaecol Obstet. 2003 Jun; 81(3):267-71.

18. Ferns SJ, Bhat BV, Basu D.Value of nucleated red blood cells in predictingseverity and outcome of perinatalasphyxia. Indian J Pathol Microbiol.2004 Oct; 47 (4):503-5.

19. Roberton's Textbook of Neonatology $4^{\mathrm{TH}}$ Edition, Neonatal anaemia and red cell disorders, chapter-30, Haematology, Irene AG Roberts, Neil A Murray.740

20. Ruth V, Fyhrquist F, Clemons G, Raivio KO. Cordplasma vasopressin, erythropoietin, and hypox- anthine as indices of asphyxia at birth. Pediatr Res. 1988 Oct;24(4):490-4.

21. Brucknerová I, Benedeková M, Pechán I, Holomán K, Bieliková E, Kostrová A, Ujházy E, Dubovický M, Mach M. Delivery as a "physiological stress" and its influence on some parameters of oxidative stress. Neuro Endocrinol Lett. 2006 Dec;27 Suppl 2:65-8.

22. Ramesh R Pol, Ramesh Pattar, Anilraj, et al. Haematological Parameters for Early Assessment of Severity of Birth Asphyxia. International Journal of Current Medical And Applied Sciences, 2015, July, 7(2), 91-93.

23. Brucknerova L, Benedekova M. Asphyxia of the newborn- the ever topical problem. Biologia. 2000 Jan; 55 (8):23-6.

\section{How to cite this article?}

Koreti S, Eske G.S, Gaur A, Gupta A. Study of hematological parameters among newborns with perinatal asphyxia.Int J Pediatr Res. 2018;5(3):122-129. doi:10.17511/ijpr.2018.i03.04. 